$\xi=-$ 国

\title{
Incorporation of Alternative Fuels and Raw Materials (AFR) to Produce a Sustainable Cement
}

\author{
Ali Benlamoudi ${ }^{1}$, Aeslina Abdul Kadir ${ }^{1 *}$, Mohamed Khodja ${ }^{2}$ \\ ${ }^{1}$ Faculty of Civil and Environmental Engineering, University Tun Hussein Onn Malaysia (UTHM), \\ 86400, Parit Raja, Batu Pahat, Johor, Malaysia \\ ${ }^{2} 3$ Division Research \& Development SONATRACH/Central Direction of Research \& Development, \\ Avenue Novemberlst, 35000 Boumerdes, Algeria \\ *Corresponding author E-mail: Aeslina@uthm.edu.my
}

\begin{abstract}
Throughout the last two decades, tremendous researches have been carried out to investigate the possibility to reduce the cement plants' costs in terms of raw materials and fuel consumption. Different types of alternative fuels and raw materials (AFR) have been used and proved their efficiencies such as sewage sludge, used tires, crushed aggregates, refuse derived fuel (RDF), red mud, ash and others. Generally, it has been deduced that the possibility to incorporate AFR to produce an acceptable quality of cement is related mainly to its calorific value and its chemical composition. As results, it was reported that incorporation of AFR has reached up to $100 \%$ for raw materials substitution and more than $30 \%$ for fossil fuel replacement. Nevertheless, the AFR may contain toxic components such as volatile content and heavy metals that need careful attention in its decisive use since it may pose serious problems to the environment and the living things. More parameters may affect the cement production cost including the moisture content of AFR, the burning temperature, the residential time, the accessibility to the AFR, the easy handling and others. The high moisture content of the AFR may increase the total cost of cement production because of the need of a high thermal energy to dry it prior to be incorporated into cement plant. Same thing goes with temperature needed by the AFR to be burned within the kiln. This overview summarizes the studies throughout the last two decades related to cement manufacturing by using AFR based on the main parameters studied by the researchers, the main advantages and the main disadvantages.
\end{abstract}

Keywords: AFR; Alternative Fuel; Calorific Value Cement; Raw Materials.

\section{Introduction}

The increase in demand of cement at the international market level has pushed contractors to double their production, which has resulted in natural resources depletion and greenhouse gases (GHG) increase. Few years back, many studies were achieved to reduce the cost of cement production. Different types of alternative fuel and raw materials (AFR) were incorporated into cement production and showed good performance. These AFR fall under the three states of matter: liquid, solid and gas.

Many parameters have been taken into account mainly s chemical analysis, calorific value, temperature, moisture content and others However, incorporation of the waste materials in cement plants, although offer valuable advantages like reducing fuel and raw material consumption, decreasing of stack gases, elimination of waste from the environment and others; but it still has some drawbacks like existing of heavy metals, extension of setting time, presenting of high volatile content and others. As examples, the presence of chlorine content may weaken the cement product quality [1], affect the quality of cement by increasing the stability of the belite structure, delay the alite crystallization or reduce the viscosity of the interstitial phase [2]. Moreover, the presence of trace elements associated to the waste may lower the clinker burnability and lower the temperature required for the formation of liquid phase as well as for the acceleration of sintering process [3]. Hence, this may lead to the release of the unburned heavy metals that pollute the groundwater through leaching. In addition to that, incorporation of AFR may increase the UCS of cement and decrease the setting time $[4,5,6]$. Moreover, the high volatile content of the AFR cause blockage of the kiln; and extra amounts of $\mathrm{Zn}$ out of the range of 0.01 to $0.2 \%$ may cause cement setting problems [7].

This overview summarizes the studies throughout the last two decades related to cement manufacturing by using AFR based on the main parameters studied by the researchers, the main advantages and the main disadvantages.

\section{Alternative Fuels and Raw Materials (AFR)}

The world business council for sustainable development defines the alternative fuels and raw materials (AFR) as selected wastes and by-products containing useful substances that can be used as raw materials to replace the natural raw materials [8]. In other words, the AFR refer to the wastes used to substitute partially or fully the fossil fuel and the natural mineral resources in a waste management scheme called co-processing [9]. In fact, differentiation between alternative fuels and alternative raw materials are not clear since the majority of the materials possess both useful minerals content and recoverable calorific value. Various types of materials have been used, and these materials are categorized into the three basic groups: gas, liquid and solid. The gaseous wastes are landfill gas, pyrolytic gas, biogas and others. The liquid waste 
are used oils, solutions exhausted from surface treatment bath with cyanide from electroplating operations, asphalt emulsion (in solvent), paraffin solvent with paint, dirt solvents, mix resin with solvent, triethylene-glycol and others. The solid are used tires, wood waste, plastics, papers, biomass, municipal waste, textiles sludge, soil contaminated with oil, soluble oil, oil in emulsion, dirty oil, used grease, petroleum sludge, waste clean-up, slag molten of aluminium, iron, steel, and zinc, waste of non-metallic minerals, wastes from incineration or thermal treatment of contaminated soil and others $[10,11,12]$.

Different characteristics of AFR should be analysed beforehand in order to determine their suitability to be incorporated into industrial production. These characteristics may include: chemical compositions: $\mathrm{SiO}_{2}, \mathrm{CaO}, \mathrm{Fe}_{2} \mathrm{O}_{3}, \mathrm{Al}_{2} \mathrm{O}_{3}, \mathrm{MgO}$ and $\mathrm{K} 2 \mathrm{O}$; elementary composition: $\mathrm{H}, \mathrm{C}, \mathrm{N}, \mathrm{S}$ and $\mathrm{O}$; heavy metals and hydrocarbons: $\mathrm{Zn}, \mathrm{Pb}, \mathrm{Cd}, \mathrm{Cr}, \mathrm{Hg}, \mathrm{Ag}, \mathrm{Se}$, fluorine, pyrene, chrysene and benzo[a]pyrene; volatile content; calorific value and moisture content $[13,2]$.

Natural resources depletion and increase in gases emitted to the environment have promoted contractors to substitute the fossil fuels and the raw materials by different AFR into industrial plants like bricks, fertilizer, cement, paper production and others. Cement production has marked more attention amongst the materials since its need is heavily increased. Substitution within cement plants has implemented several types of AFR such as: sewage sludge [14, 2], used tires [7], crushed aggregates [15], refuse derived fuel (RDF) [1, 16, 17], red mud [18], ash [6, 19] and others. This incorporation reached up to $100 \%$ of raw materials substitution and up to $30 \%$ of fossil fuel replacement.

Specific principles should be considered prior to use AFR into industrial production in order to ensure the sustainability of the whole production process. These principles may include the identification of AFR before being accepted. In other words, the AFR must not introduce chemical species into the production process that might be deleterious to the stability of the process or the performance of the product [20]. Calorific value, which is the energy released as heat when the material undergoes a complete combustion [21], is worth also to be considered when a kind of waste material is intended to replace the fossil fuel. This value must be stable enough and exceed the minimum value required for the industrial processing so as to play an efficient role in the substitution operation. Another principle for the use of AFR is that the entire supply chain associated with production, transportation and use of waste should be positive compared to conventional fuels, meaning that the GHG should be lesser by using the AFR [22]. In the same way, the usage of AFR should be done in a way that assure the environmental production [23] and does not adversely disturb the biodiversity, so it must protect the ground and the air and the water qualities.

For cement production, different parameters were taken into account to the AFR prior to be incorporated into the production plants so as to eliminate their negative impacts. In fact, no specific criteria have been set toward this matter yet [24]. However, the adaptation have been set by individuals and have been based on easy handling of the AFR, its availability, its different characteristics including calorific value, moisture, volatile and ash content and others [25]. As an example, cement Polska group has set some criteria that include $14 \mathrm{MJ} / \mathrm{kg}$ of calorific value, $0.2 \%$ of chlorine content, less than $2.5 \%$ of sulfur content, less than parts per million ( $\mathrm{ppm}$ ) of polychlorinated Biphenyls (PCBs) content and less than $2500 \mathrm{ppm}$ of heavy metals content [26]. More details about the criteria and their influence on the cement manufacturing are detailed in the following part.

\section{Incorporation of AFR into cement plants}

\subsection{Sewage Sludge}

All Fang et al. [14] have studied the incorporation of sewage sludge to produce the cement by supplying it into the precalciner of the cement plant. The researchers have mentioned that the calorific value of the sewage sludge is $11.15 \mathrm{MJ} / \mathrm{kg}$, which exceed the lower value needed to produce cement, which is $2.9 \mathrm{MJ} / \mathrm{kg}$ [27]. They have concluded also that the chemical compositions of the sludge are out of the range of those of cement presented in Table 1. Thus, the sewage sludge could substitute the raw materials only with $3.6 \%$ in order to imitate the same properties of cement. This result is supported by Chinyama [28] who has declared that the sewage sludge percentage should not exceed $5 \%$ to prevent the negative impacts on the cement properties. The same study mentioned that the calorific value of the sewage sludge was 11.15 $\mathrm{MJ} / \mathrm{kg}$, which exceed the lower value needed to produce cement, which is $2.9 \mathrm{MJ} / \mathrm{kg}$ [27]. Furthermore, the study has showed that a range of 3 to $10 \%$ of sewage sludge could be incorporated into the cement plant and reduces the fuel consumption. After producing the cement, a mortar has been prepared in order to test the compressive strength after 28 curing days and the setting time. The results showed a slightly decrease in the compressive strength (59.3 MPa) compared to that of the cement without sludge (60.8 $\mathrm{MPa}$ ); and a slight increase in the setting time values that were $123 \mathrm{~min}$ and $158 \mathrm{~min}$ for the initial and the final setting times, respectively compared to those without incorporation of sludge, which were $103 \mathrm{~min}$ and $140 \mathrm{~min}$ for the initial and the final setting times, respectively. However, the change in the values didn't highly affect the cement quality negatively. The advantages of this research include also the removal of NOx by $65 \%$; thus, reducing its danger from the environment. The study has not mentioned any disadvantages of the sewage sludge in case of using the same parameters and the same percentages.

Table 1: Ranges of cement compositions [28]

\begin{tabular}{|c|c|}
\hline Chemical composites & Cement (\%) \\
\hline $\mathrm{CaO}$ & $63-67$ \\
$\mathrm{SiO}_{2}$ & $19-23$ \\
$\mathrm{Al}_{2} \mathrm{O}_{3}$ & $3-7$ \\
$\mathrm{Fe}_{2} \mathrm{O}_{3}$ & $1.5-4.5$ \\
$\mathrm{MgO}$ & $0.5-2.5$ \\
$\mathrm{~K}_{2} \mathrm{O}$ & $0.1-1.2$ \\
$\mathrm{Na}_{2} \mathrm{O}$ & $0.07-0.4$ \\
$\mathrm{SO}_{3}$ & $2.5-3.5$ \\
\hline
\end{tabular}

Better findings have been achieved by Ruiz Garcia [29] who have investigated the efficiency of introducing sewage sludge into cement plants by simulating the cement kiln with a furnace as a pilot factory. The results have shown a replacement of $14 \%$ of raw materials by sewage sludge and a percentage of $34 \%$ of fuel consumption could be reduced. These results may be explained by the chemical properties of the sludge that are close to those of cement and also the high calorific value of sewage sludge $(8.30 \mathrm{MJ} / \mathrm{kg})$, which is sufficient for this material to be considered as a viable supplementary fuel in cement production. Technical advantages of the incorporation of sewage sludge in Ruiz Garcia's study were the reduction of the free lime content in the clinker and the complete disposal of the sewage sludge. The only disadvantage mentioned by this research was the slight reduction in alite formation, but it did not affect the total cement production negatively.

The usage of $15 \%$ of sewage sludge has been demonstrated by Lin et al. [30] to replace the cement raw material without significant negative impacts. The results indicated that the major components of eco-cement (cement incorporated with sludge) were similar to those of Ordinary Portland Cement. Also, the leaching concentrations of the eco-cement met the standard of the Chinese regulatory thresholds. Nevertheless, the study concluded that incorporation of $15 \%$ of sewage sludge delayed the clinker hydration, decreased the flexural strength at early ages and delayed the setting time. However, it was mentioned also that there was no significant effect on both compressive and flexural strengths at later curing ages. In other study, Xu et al. [3] have corrected the dried sludge by 
$10 \%$ of lime (LDS10) prior to be used as raw material for cement production. They have come out with the result that $15 \%$ of LDS10 could be a good substitution for the cement raw materials. Also, incorporation of LDS10 has shown less carbon dioxide emission. Nevertheless, the study reported that the addition of trace elements contained in the sludge has lowered the clinker burnability and has decreased the temperature required for the formation of liquid phase as well as for the acceleration of sintering process.

Another work have been conducted by Yen et al. [31] who have incorporated sewage sludge together with Marble sludge, Drinking Water treatment Plant Sludge (DWTPS) and Basic Oxygen Furnace Sludge (BOF), respectively, to replace the raw materials, which are: sand, limestone, clay and iron slag, respectively. The study was in a pilot factory, and the substitutions were implemented based on the percentages of the waste materials those imitate the percentages of the raw materials needed to produce cement. As results, the sewage sludge has shown a good performance in replacing $100 \%$ of the sand needed. Same result for the DWTPS and BOF in substituting the clay and the iron slag, respectively. But for the marble sludge, the study has indicated its feasibility to replace the limestone only up to $50 \%$. However, the intensity peaks of $\mathrm{C} 3 \mathrm{~S}$ appeared in the control clinkers at $2 \theta$ equal $29.5^{\circ}$ and $51.4^{\circ}$ did not happen in cement with total replacement of limestone by marble sludge. These results are due to lowering in pouring temperature of the clinker in the sintering process and preventing the $\mathrm{C} 2 \mathrm{~S}$ from transferring into $\mathrm{C} 3 \mathrm{~S}$. This study has not mentioned any drawbacks for the substitution of the raw material by the waste sludges. Water purification Sludge (WPS) have been studied by Chen et al. [4] who have concluded that up to $10 \%$ of WPS was able to substitute the cement raw materials required for cement production. However, addition of WPS to the raw mixture have lowered the free lime content, increased the UCS values, increased the amount of $\mathrm{C} 3 \mathrm{~S}$ and increased the ratio of $\mathrm{C} 3 \mathrm{~A}$ to $\mathrm{C} 4 \mathrm{AF}$. In addition to that, the negative impacts were limited due to the low concentrations of $\mathrm{Cu}, \mathrm{Cr}, \mathrm{Zn}$, and $\mathrm{Ni}$ in the raw mixture.

\subsection{Refused derived sludge}

Refuse Derived Fuel (RDF) is considered as a promised alternative fuel for cement plants due to its high calorific value. Kara et al. [1], Kara M. [16] and Rovira et al. [17] have studied the incorporation of this material into cement kiln by replacing the fossil fuel. As results, RDF has been found to provide partial replacement of $20 \%, 15 \%$ and $15 \%$ of the total fuel required for the cement production process for the three studies, respectively. Moreover, the RDF has shown a very low moisture content $(25 \%)$, which does not need much energy for preheating before proceeding to the kiln. The authors came out with several advantages of using the RDF, including: reduction in cement production cost and landfill disposal, production of beneficial effects on air emission and ash residue when used as fuel [16], preservation of resources, significant reduction for a number of pollutants (PCDD/Fs, Co, Cr, $\mathrm{Mn}$ and $\mathrm{Ni}$ ) in vegetation, as well as $\mathrm{Ni}$ in soil $\mathrm{Sn}$ and air [17] and others. In the other side, the three studies have not shown any disadvantages towards the quality of clinker produced.

\subsection{Recovered Fuel (SRF)}

Close to the RDF results, Conesa et al. [32] have studied the incorporation of Solid Recovered Fuel (SRF). They have investigated its efficiency use within the cement kiln. However, SRF showed very low moisture content, which was $16.7 \%$ that did not need high energy to be dried prior to use in cement kiln, this is one of the advantages of using SRF. Moreover, it possessed a very high calorific value, which was $17.74 \mathrm{MJ} / \mathrm{kg}$ that has permitted an average feed rate of $10 \mathrm{t} / \mathrm{h}$, while the average clinker production was estimated at $120 \mathrm{t} / \mathrm{h}$. In addition to that, addition of SRF into cement plant came out with decreasing in $\mathrm{NO}_{\mathrm{x}}$ and $\mathrm{SO}_{2}$.

\subsection{Red-Mud}

Red-mud is another waste that has been incorporated by several studies into cement plants. This waste, which is a solid residue of the caustic Soda digested of bauxite ore, has six major components, namely: $\mathrm{SiO} 2, \mathrm{Fe} 2 \mathrm{O} 3, \mathrm{Al} 2 \mathrm{O} 3, \mathrm{CaO}, \mathrm{TiO} 2$, and $\mathrm{Na} 2 \mathrm{O}$. These components are very close to those of cement, what has attracted many researchers to use it as raw material to substitute those of cement. Tsakiridis et al. [18] and Singh et al. [21] have conducted simulations of producing cement in pilot factors by incorporating the red mud into cement raw materials. As results, Tsakiridis et al. have concluded that $3.5 \%$ of red mud could partially substitute the raw materials without any obvious changing in the cement mineralogical composites, and even the mechanical properties were very close to those of cement without red mud. However, even though $3.5 \%$ of red mud is a very small quantity, but the huge amounts of cement needed may cover the entire RM existed in nature, which may keep the environment far from its bad impacts. Singh et al. [21] in their study have concluded that an amount of $35 \%$ of RM together with $15 \%$ of Bauxite and $50 \%$ of lime could produce an eco-cement close in its properties to that of Ordinary Portland Cement (OPC). Both studies have not shown significant disadvantages on the cement final product. Vangelatos et al. [33] have studied the dewatered RM by means of a filter press; the residue was named Ferro alumina. As results, incorporation of $5 \%$ of Ferro alumina has not affected qualitatively the mineralogical phases formed in the produced clinkers; it has shown a decrease in free lime content, the change in setting times has been negligible and a slight increase in UCS has been noted.

\subsection{Ash}

Ash from different origins contains heavy metals that cause serious danger to the environment and the living things. It has been implemented into cement plants, even with low percentages, but it might eliminate its danger through the encapsulation of heavy metals during the clinker formation. Pan et al. [5] have investigated the use of Municipal Solid Waste Incineration (MSWI) bottom and fly ash to produce cement. The results showed that $1.75 \%$ and $3.75 \%$ of fly and bottom ash could be involved into cement production. The chemical analysis of the new cement (with ash) has showed very near mineralogical composites to the cement without ash, the same thing for the UCS, but the setting times were slightly longer. The addition of MSWI ash in cement raw materials did not affect the cement quality; nevertheless, their amounts were limited by the salts, especially chlorides, which can be effectively removed by water and/or acids.

Tay and Show [6] have concluded that the palm oil ash could substitute the raw material needed for cement with $10 \%$, taking into account the increase in setting time and the decrease in UCS. It has been noted that even the delaying in setting time was within the ASTM standard, but the cement produced needs one year to fulfill the requirement. Thus, palm-oil ash at this percentage has not promised to be used substantially as a cement replacement material only after long curing time.

Trezza and Scian [13] have studied the incorporation of the used oil ash in cement production. They showed that a quantity of $0.04 \%$ showed a higher performance than that of cement without ash. Lin and Lin [19] came out with a result that it is feasible to use sludge ash and ferrate waste to replace up to $20 \%$ of the mineral components of the raw materials of cement, when the ash was composed of $9.72 \%$ of water purification sludge ash (WPSA), $5 \%$ of primary sewage sludge ash (PSSA), and $6.84 \%$ of industrial wastewater sludge ash (IWSA), and the ferrate represented $1.97 \%$. This research provided some advantages that are the increase in UCS, the decrease in raw material consumption, and the matching of leaching concentrations to the regulatory limits. 


\subsection{Solid wastes}

Different types of glasses have been studied by Wong et al. [34] to substitute the raw material prior to cement production. At first glance, the general composition of glass fits to the requirement of the raw materials for cement production. As results, the glass could substitute up to $0.6 \%$ of the raw materials fed to the cement kiln and the exhaust from the stack has not shown significant changes in the concentration of pollutants.

Another work has been studied by Pipilikaki et al. [7] on Tire Derived Fuel (TDF). They have concluded that $6 \%$ of the total fuel could be reduced by TDF and the results were very effective. In addition, the use of TDF as an alternative fuel is a cost effective; also, the steel component of the tire can substitute the iron that may reduce the cost of iron acquisition. Moreover, the difference in UCS value with using TDF compared to the control cement is practically invisible after 28 curing days. Some drawbacks for implementing TDF may include blockage in the kiln due to high volatile content and setting problems in case of extra amounts of zinc. Towards that, careful attention should be associated.

For petroleum sludge (PS), researches related to its incorporation into cement plants are very scarce. However, In 2006, MVW Lechtenberg \& Partner company have carried out the first studies on the PS and concluded that it is feasible to be incorporated into cement plants as fuel substitution since the samples have shown very high calorific value ( $3871 \mathrm{kcal} / \mathrm{kg}=16.2 \mathrm{MJ} / \mathrm{kg}$ ) [20], which exceed the minimum value required for cement production [27] Moreover, the same study has deduced that the use of PS in cement kiln is highly recommended since it provides complete incorporation of the remaining ash into cement matrices and provides also aluminum, silica, clay and other minerals to the cement raw materials [33]. In fact, in this study, information related to the percentage of PS and its disadvantages has not been published since the study has been carried out within the company and the data are for the internal use only.

The best implementation of AFR (in terms of percentage substitution) was that of incorporating Recycled Concrete Aggregates (RCA) and the Recycled Masonry Aggregates (RMA) into cement plant. The study has been conducted by Galbenis and Tsimas [15] who have revealed that $100 \%$ of the raw material could be substituted by RCA together with RMA with percentages of 77 and 33 respectively. The results have improved the burnability of the raw meals and have not shown any negative impact on the clinker properties.

\subsection{Others types of wastes}

Inorganic sludges have partially substituted the raw materials to produce cement. Alp et al. [35] and Alp et al. [36] have studied the incorporation of pyrite cinder, which is the waste products of sulfuric acid plant, and flotation wastes of copper slag (FWCS), respectively. They have concluded that both pyrite cinder and FWCS are suitable materials as iron sources for the production of Portland cement clinker due to the high content of Fe2O3. For the two wastes, a percentage within the range of [2.5-6] could substitute the iron raw material and led to insignificant change in UCS and setting time compared to ordinary Portland cement type I (CEM I). For the phosphate-coating sludge, it has been carried out by Caponero and Tenorio [36] and showed that its incorporation up to $5 \%$ in cement production has shown neither significant modification in the yielded clinker proportional to the sludge additions, nor atypical phases formed. Nevertheless, a careful measure should be maintained towards the zinc quantities to ensure its rate that fit to the regularity limits. Lairaksa et al. [38] have concluded that implementing of cathode ray tube waste (CRT) into cement production process up to $0.5 \%$ has not marked significant influence on the alkali content of the cement clinker mixtures, and particularly incorporation of $0.10 \%$ of CRT demonstrated the best encapsulation ability. Although the results have indicated minimal losses in mixtures containing $0.1 \%$ CRT, the specific maximum concentration that ensured that total encapsulation of lead and the non-contamination of lead through emission must be determined. Tsakiridis et al. [39] have mentioned that the Jarosite- Alunite residue, produced during hydrometallurgical treatment of nickel oxide ores with sulphuric acid, can be utilized as a raw material in cement production. In addition, the values for setting times were similar to those obtained from the reference ordinary Portland cement sample and within the standard limits. Also, the compressive strengths were at least as high as those of the reference sample during hydration. In another study, Gazquez et al. [40] have shown that the $\mathrm{TiO} 2$ industry red gypsum waste (RG) could replace the total amount of gypsum needed to produce cement and saved 4 to $5 \%$ of the clinker, while maintaining similar properties to the components found in OPC. Therefore, a proportion of RG as high as $10 \%$ can be used in the cement manufacturing, while still complying with all qualities required.

\section{Conclusion}

Disposing of alternative fuel and raw materials (AFR) by their incorporation into cement plants has been studied widely by researchers as a mean of minimizing the amount of fuel and raw materials consumption and the GHG emission as well. Generally, it has been deduced that the possibility to incorporate AFR to produce an acceptable quality of cement is related usually to its calorific value and its chemical composition. However, the high percentage of the AFR in cement plant is referred mainly to the closest components to the substitute and vice versa. In the same way, the high incorporation of AFR is referred to its high calorific value. Through literature, it was reported that incorporation of AFR reached up to $100 \%$ for raw materials substitution and up to $30 \%$ of fossil fuel replacement. From another side, the AFR may contain toxic components such as volatile content and heavy metals that need careful attention in its decisive use since it may pose serious problems to the environment and the living things. More parameters may affect the cement production cost including moisture content of AFR, burning temperature, residential time, accessibility to the AFR, easy handling and others. The high moisture content of the AFR may increase the total cost of cement production because of the need of a high thermal energy to dry it prior to be incorporated into cement plants. Same thing goes with temperature needed by the AFR to be burned within the kiln. Incorporation of more types of industrial wastes is worth to be studied such as petroleum sludge, which contains a high calorific value [20] and very similar components to those of cement [41]. Moreover, a database contains different parameters of AFR should be established in order to ease the decision of any type of waste prior to be incorporated into cement plants.

\section{Acknowledgement}

The authors want to thank the University Tun Hussein Onn Malaysia (UTHM) for the facilities provided to achieve this work. Special thanks to Office for Research , Innovation, Commercialization, Consultancy Management (ORICC) for providing the grant under the vot number: U581.

\section{References}

[1] Kara M, Günay E, Tabak Y, Yıldız Ş \& Enç V (2008), The usage of refuse derived fuel from urban solid waste in cement industry as an alternative fuel, Proceeding of The 6th IASME/WSEAS International Conference on Innovation Heat Transfer, Thermal Engineering and Environment (HTE'08), pp, 20-22.

[2] Rodríguez NH., Martínez-Ramírez S, Blanco-Varela MT, Donatello S, Guillem M, Puig J, Fos C, Larrotcha M \& Flores J (2013), The effect of using thermally dried sewage sludge as an alternative fuel on Portland cement clinker production. Journal of Cleaner Production 52, 94-102. 
[3] Xu W, Xu J, Liu J, Li H, Cao B, Huang X \& Li G (2014), The utilization of lime-dried sludge as resource for producing cement Journal of Cleaner Production 83, 286-293.

[4] Chen H, Ma X \& Dai H (2010), Reuse of water purification sludge as raw material in cement production. Cement and Concrete Composites 32, 436-439.

[5] Pan JR, Huang C, Kuo JJ \& Lin SH (2008), Recycling MSWI bottom and fly ash as raw materials for Portland cement. Waste Management 28(7), 1113-1118.

[6] Tay JH, Show KY (1995), Use of ash derived from oil-palm waste incineration as a cement replacement material. Resources, Conservation and Recycling 13(1), 27-36.

[7] Pipilikaki P, Katsioti M, Papageorgiou D, Fragoulis D \& Chaniotakis E (2005) Use of tire derived fuel in clinker burning. Cement and Concrete Composites 27(7-8), 843-847.

[8] Guidelines for the Selection and Use of Fuels and Raw Materials in the Cement Manufacturing Process, World Business Council for Sustainable Development, (July 2014).

[9] Guidance Manual on the Use of Alternative Fuel and Raw Materials in Cement Kiln Co-processing, Department of science and technology, Industrial technology development institute in incorporation with CeMAP. Environmental management bureau, (2008).

[10] de Queiroz Lamas W, Palau JC \& de Camargo JR (2013), Waste materials co-processing in cement industry: Ecological efficiency of waste reuse. Renewable and Sustainable Energy Reviews 19, 200-207.

[11] Popovics S (1993), Portland cement-fly ash-silica fume systems in concrete. Advanced Cement Based Materials 1(2), 83-91.

[12] Carpio RC, Sousa Júnior FD, Coelho LD \& Silva RJ (2008), Alternative fuels mixture in cement industry kilns employing particle swarm optimization algorithm. Journal of the Brazilian Society of Mechanical Sciences and Engineering 30(4), 335-340.

[13] Trezza MA \& Scian AN (2000), Burning wastes as an industrial resource: Their effect on Portland cement clinker. Cement and Concrete Research 30(1), 137-144.

[14] Fang P, Tang ZJ, Huang JH, Cen CP, Tang ZX \& Chen XB (2015), Using sewage sludge as a denitration agent and secondary fuel in a cement plant: A case study. Fuel Processing Technology 137, 1-7.

[15] Galbenis CT \& Tsimas S (2006), Use of construction and demolition wastes as raw materials in cement clinker production. China Particuology 4(02), 83-85.

[16] Kara M (2012) Environmental and economic advantages associated with the use of RDF in cement kilns. Resources, Conservation and Recycling 68, 21-28.

[17] Rovira J, Mari M, Nadal M, Schuhmacher M \& Domingo JL (2010), Partial replacement of fossil fuel in a cement plant: Risk assessment for the population living in the neighborhood. Science of the Total Environment 408(22), 5372-5380.

[18] Tsakiridis PE, Agatzini-Leonardou S \& Oustadakis P (2004), Red mud addition in the raw meal for the production of Portland cement clinker. Journal of Hazardous Materials 116(1-2), 103-110.

[19] Lin KL \& Lin CY (2005), Hydration characteristics of waste sludge ash utilized as raw cement material. Cement and Concrete Research 35(10), 1999-2007.

[20] Lechtenberg D (2010) Waste management and cement industries in Arab Countries. Cement and building materials review, 27-34

[21] Singh, M, Upadhayay S \& Prasad P (1996), Preparation of special cements from red mud. Waste Management 16(8). 665-670.

[22] Guidelines for Cement Sustainability Initiative (CSI) CoProcessing Fuels and Raw Materials in Cement Manufacturing, World Business Council for Sustainable Development (WBCSD). Version 2.0 (2014).

[23] Sewage Sludge: Operational and Environmental Issues, Foundation for Water Research.: FR/R001: Marlow: the U. K., (2011) (third edition).

[24] Giannopoulos D, Kolaitis DI, Togkalidou A, Skevis G \& Founti MA (2007), Quantification of emissions from the co-incineration of cutting oil emulsions in cement plants-Part I: NO x, CO and VOC. Fuel 86(7), 1144-1152.

[25] Rahman A, Rasul M, Khan MM \& Sharma S, Industrial waste as alternative fuel in cement industry: its impact on environment. Recent researches in environmental and geological sciences, proceedings of the 7th WSEAS International Conference on Energy \& Environment (EE'12), WSEAS Press, (2012)

[26] Mokrzycki E, Uliasz-Bocheńczyk A \& Sarna M (2003), Use of alternative fuels in the Polish cement industry. Applied Energy.74(1), 101-111.
[27] Best Available Techniques (BAT) Reference Document for the Production of Cement, Lime and Magnesium Oxide, European Integrated Pollution Prevention Control Bureau (EIPPCB). Publications Office of the European Union: Luxembourg, (2015).

[28] Chinyama MP, Alternative fuels in cement manufacturing. INTECH Open Access Publisher, (2011).

[29] Ruiz Garcia M, Preparation of waste derived fuels and their evaluation in the cement industry, proceedings of the 1st National Conference for Small and Medium Enterprises and the Environment (COPYMA) Estella, Navarra, Spain, (2009) (in Spanish).

[30] Lin Y, Zhou S, Li F \& Lin Y (2012), Utilization of municipal sewage sludge as additives for the production of eco-cement. Journal of Hazardous Materials 213-214, 457-465.

[31] Yen CL, Tseng DH \& Lin. TT (2011), Characterization of ecocement paste produced from waste sludges. Chemosphere 84(2), 220-226

[32] Conesa JA, Rey L, Egea S \& Rey MD (2011) Pollutant formation and emissions from cement kiln stack using a solid recovered fuel from municipal solid waste. Environmental science \& technology 45(13), 5878-5884

[33] Vangelatos I, Angelopoulos GN \& Boufounos D (2009) Utilization of ferroalumina as raw material in the production of Ordinary Portland Cement. Journal of Hazardous Materials 168(1), 473-478.

[34] Chen G, Lee H, Young KL, Yue PL, Wong A, Tao T \& Choi KK (2002), Glass recycling in cement production - an innovative approach. Waste Management 22(7), 747-753.

[35] Alp İ, Deveci H, Yazıcı EY, Türk T \& Süngün YH (2009), Potential use of pyrite cinders as raw material in cement production: Results of industrial scale trial operations. Journal of Hazardous Materials $166(1), 144-149$.

[36] Alp İ, Deveci H \& Süngün H (2008), Utilization of flotation wastes of copper slag as raw material in cement production. Journal of Hazardous Materials. 159(2-3), 390-395

[37] Caponero J \& Tenório JAS (2000), Laboratory testing of the use of phosphate-coating sludge in cement clinker. Resources, Conservation and Recycling 29(3), 169-179.

[38] Lairaksa NA, Moon R \& Makul N (2013), Utilization of cathode ray tube waste: Encapsulation of $\mathrm{PbO}$-containing funnel glass in Portland cement clinker. Journal of Environmental Management 117, 180-186.

[39] Tsakiridis PE, Agatzini-Leonardou S, Oustadakis P, Katsioti M \& Mauridou E (2005), Examination of the jarosite-alunite precipitates addition in the raw meal for the production of portland cement clinker. Cement and Concrete Research 35(11), 2066-2073.

[40] Gazquez MJ, Bolivar JP, Vaca F, García-Tenorio R \& Caparros A (2013), Evaluation of the use of $\mathrm{TiO} 2$ industry red gypsum waste in cement production. Cement and Concrete Composites 37, 76-81.

[41] Prakash V,Saxena S, Sharma A, Singh S \& Singh SK (2015), Treatment of Oil Sludge Contamination by Composting. Journal of Bioremediation \& Biodegradation 6(3), 1. 